\title{
LA CONTROVERSIA SOBRE EL ABORTO EN LOS ESTADOS UNIDOS: LAS DIMENSIONES CONSTITUCIONALES
}

Robert S. Barker

Hace más de 200 años, el jurista inglés sir William Blackstone, en su tratado clásico Comentarios sobre las Leyes de Inglaterra, dijo lo siguiente:

"La Vida es el obsequio principal de Dios, un derecho inherente por naturaleza a todo individuo; y ella comienza para el Derecho desde el momento en que una criatura es capaz de moverse en el vientre de su madre. Puesto que si una mujer está embarazada y mediante una pócima o cualquier otro medio matase al niño en su seno; o si alguien la golpease y por ello el niño muriera dentro de su cuerpo y ella diera a luz una criatura muerta; este acto, si bien no es asesinato, sería considerado, según la antigua ley, un homicidio simple o un homicidio por negligencia. continúa siendo una falta atroz. (1)."

Esta afirmación de Blackstone sobre el aborto reflejaba no sólo los principios del Derecho Consuetudinario inglés, que los Estados Unidos heredó y adoptó, sino que también expresaba la tradición legal de toda la civilización occidental (2). La referencia a "los movimientos iniciales del feto en el vientre materno" reflejaba el estado rudimentario del conocimiento médico en el siglo XVIII. Ahora sabe-

(1) BLACKSTONE, W. Comentarios sobre las Leyes de Inglaterra. 125126 (1a. edic. 1765).

(2) GRANDFIELD, D. La Decisión sobre el Aborto. 45-79. 
mos que las cualidades humanas que eran identificadas en ese entonces con los movimientos fetales, en realidad existen desde el momento de la concepción (3). El punto es que la tradición legal anglo-americana - tanto civil como eclesiástica - siempre ha considerado al aborto como un grave error porque, en palabras de Blackstone, priva a una persona de un derecho inherente por naturaleza a todo individuo - el derecho a la vida, que es el regalo más importante que nos da Dios.

En los Estados Unidos, debido a la naturaleza federal de su sistema legal, el aborto, al igual que la mayoria de delitos comunes, fue normado por los Estados y no por el gobierno nacional. Y si bien las leyes de los Estados variaban de tiempo en tiempo y de lugar a lugar, el aborto, en la mayor parte de circunstancias, estaba prohibido en todas partes (4). Esto, evidentemente, ha cambiado en forma significativa y no a causa de alguna acción legislativa ni de una exigencia popular sino debido a la sentencia de la Corte Suprema de los Estados Unidos en 1973, en el ahora famoso caso de Roe contra Wade (5). Sin embargo, una comprensión del tratamiento del aborto por parte de la Corte Suprema no comienza con un examen de este caso, sino que se inicia por lo menos unos ocho años antes, en 1965, con la sentencia de la Corte en el caso conocido como Griswold contra Connecticut (6).

En el caso Griswold, varios litigantes arguyeron que una ley del Estado de Connecticut que prohibía la venta y uso de anticonceptivos violaba la Constitución. Aun cuando dicha ley casi nunca había sido aplicada y aunque la Constitución no decía nada sobre dicha materia, la Corte resolvió que la ley era inconstitucional. La Corte hizo esto declarando, primero, que la Constitución contiene una garantía implícita de lo que llamó un "derecho a la intimidad" (7). Entonces

(3) NATHANSON, B. Abortando América . 199-211.

(4) GRANFIELD. Supra, № 2 en pp. 74-75.

(5) 410 U.S. 113,93 S.Ct. 705, 35 L. Ed. 2a. 147 (1973).

(6) 381 U.S. 479,85 S.Ct. 1678,14 L. Ed. 2a. 510 (1965).

(7) 85 S.Ct. en 1681-1682. 
arribó a la conclusión de que este "derecho a la intimidad" se aplica a las relaciones esposo-esposa, madre-hijo, y a otras relaciones íntimas no especificadas, e incluye el derecho a utilizar anticonceptivos (8).

Por la misma época -y por primera vez - varios grupos en los Estados Unidos iniciaron una campaña para legalizar el aborto. La organización Paternidad Responsable abandonó su tradicional oposición a él y se adhirió a esta nueva causa (9). La Unión Americana de Libertades Civiles, apartándose de su tradicional énfasis en las libertades civiles se transformó en una abierta defensora del aborto (10). A principios de los años 70, dos casos de aborto llegaron ante la Corte Suprema; uno de Georgia y otro de Texas. Ambos involucraban a mujeres cuyos intentos para que se les practicaran abortos habían sido rechazados debido a leyes estatales. La Corte resolvió ambos casos en enero de 1973, iniciando su fundamentación con la ratificación de su posición en el caso Griswold, de que hay un derecho constitucional a la intimidad, y de que la decisión de una mujer sobre si desea o no llevar en su vientre a su hijo (la Corte no dijo "hijo" sino "feto") era parte de ese derecho a la intimidad. La Corte continuaba diciendo que, a menos que el Estado pudiese demostrar que tenía un "interés apremiante" por evitar el aborto, entonces los deseos de la madre, esto es, su derecho a la intimidad, debían prevalecer (11). La Corte luego procedía a examinar las diferentes razones que un Estado podría tener para prohibir el aborto.

La Corte señalaba que cualquier interés estatal en desalentar la conducta sexual ilícita era victoriano, arcaico y por lo tanto no debía ser tomado en cuenta en forma seria (12).

(8) Id.

(9) DONOHUE, W. La Política de la Unión Americana de Libertades Civiles. 95-96.

(10) Id. en 95-103.

(11) 93 S.Ct. en 726-728.

(12) Id. en 724. 
Luego decía que el interés del Estado en proteger la vida y la salud de la madre no era pertinente durante los tres primeros meses de gestación, porque los procedimientos médicos eran tan buenos que los abortos eran seguros durante esa etapa; pero después de los tres meses el Estado podía restringir los abortos con la finalidad de proteger la vida y la salud de la madre (13).

El Estado de Texas arguyó que tenía un interés apremiante en proteger la vida del niño por nacer. Aquí la Corte realizó su más importante declaración: dijo que un feto no es una persona; es decir, un niño aún no nacido no tiene derecho a las protecciones dadas por la Constitución a las "personas" (14). La Corte fue más allá y dijo que no sólo la Constitución no protege al niño no nacido aún, sino que tampoco los Estados tenían ningún interés apremiante en proteger la vida del niño sino hasta quizás los tres últimos meses de embarazo, porque sólo entonces es el feto "viable", es decir, sólo entonces tenía el feto el potencial para lo que la Corte llamó "una vida plena de sentido" (15). Aun entonces, prosiguió diciendo, los derechos del niño por nacer son siempre inferiores a los de la madre; esto es, la Constitución garantiza el derecho de abortar al niño en cualquier momento con el fin de proteger la vida o salud de la madre (16).

Desde el caso Roe contra Wade se han dictado numerosas sentencias por parte de la Corte Suprema y otras cortes federales de jerarquia inferior, relativas a diversas limitaciones impuestas por los Estados sobre el aborto. Algunas de ellas han ido en una dirección y otras en la otra; sin embargo, al menos hasta julio de 1989, el esquema básico establecido en Roe contra Wade fue siempre el punto de partida judicial (17).

(13) Id. en 725, $731-732$.

(14) Id. en 728-729.

(15) Id. en 730-731.

(16) Id. en 732.

(17) Véase, p.e., Paternidad Responsable contra Danforth. 428 U.S. 52, 96 S.Ct. 2831,49 L.Ed. 2a. 788 (1976); Harris contra McRae. 448 U.S. 297,100 S.Ct. 2671,65 L. Ed. 2a. 784 (1980); Akron contra Centro 
El 3 de julio de 1989, la Corte Suprema resolvió un caso: Webster contra los Servicios de Salud Reproductiva (18), que involucraba la constitucionalidad de varias disposiciones de una ley de Missouri que limitaba los abortos (19). La ley de Missouri tenía varias disposiciones cuyos fundamentos constitucionales fueron cuestionados:

Primero, el preámbulo de la ley declaraba que la vida humana se inicia con la concepción y que los niños aún por nacer tienen intereses legalmente protegidos hacia la vida, la salud y el bienestar. Este título preliminar continuaba disponiendo que todas las leyes estatales sean interpretadas en el sentido de otorgar a los niños por nacer los mismos derechos que otras personas, todo ello sujeto a las limitaciones que sobre esos derechos puedan imponer la Constitución y los precedentes de la Corte Suprema (20).

La Ley de Missouri también prohibía el uso de fondos, empleados e instalaciones públicas para realizar abortos o consejería proabortiva, a menos que fuese necesario para salvar la vida de la madre (21). La ley además exigía a los médicos que estuviesen por realizar abortos en mujeres con, por lo menos, veinte semanas de embarazo, que determinen e informen sobre la viabilidad del feto (22).

Akron para la Salud Reproductiva, Inc., 462 U.S. 416,103 S.Ct. 2481,76 L.Ed. 2a. 687 (1983); Thornburgh contra el Colegio Americano de Obstetras y Ginecólogos. 476 U.S. 747,106 S.Ct. 2169 , 90 L.Ed. 2a. 779 (1986). U.S. , 109 S.Ct. 3040,106 L.Ed. 2a. 410 (1989).

(19) Acta relacionada a la Regulación del Aborto, Comité Senatorial Suplente para el Proyecto de la Cámara No. 1596, 83va. Asamblea General, 2a. Reg. Ses. (1986), codificado en Mo.Rev.Stat. 188.010188.220.

(20) Mo.Rev.Stat. 188.010, 188.015(6).

(21) Mo.Rev.Stat. 188.205, 188.210, 188.215.

(22) Mo.Rev.Stat. 18.029. 
Cortes federales de menor jerarquía habían considerado inconstitucionales a todas esas disposiciones, pues eran violatorias de los principios de Roe contra Wade (23). La Corte Suprema revocó todas esas sentencias, con el resultado de que las disposiciones en cuestión fueron declaradas acordes con la Constitución.

La limitación de la consejería a favor del aborto fue decidida unánimemente por razones de procedimiento, no sustantivas (24).

Todos los otros puntos fueron decididos mediante votación de cinco contra cuatro. Con respecto al título preliminar, la Corte dijo que "el caso Roe contra Wade no implica ninguna limitación sobre la autoridad de un Estado para realizar una declaración que favorezca el nacimiento sobre el aborto" (25).

Con respecto a la prohibición del uso de fondos, empleados y locales públicos para llevar a cabo abortos, la Corte, nuevamente por un voto de cinco contra cuatro, señaló que un Estado puede emitir una declaración favoreciendo los nacimientos sobre el aborto y llevarla a los hechos mediante la asignación o retención de fondos públicos (26).

Con respecto a la prueba de "viabilidad", la Corte resolvió, de nuevo mediante votación de cinco a cuatro, que la ley de Missouri no era inconstitucional. Sin embargo, sobre este punto la mayoría de cinco emitió tres opiniones por separado:

El Vocal Supremo Scalia dijo que Roe contra Wade no era una interpretación legítima de la Constitución y que debía ser rechazada

(23) Servicio de Salud Reproductiva contra Webster, 851 F. 2a. 1071 (8vo. Cir. 1988); Servicios de Salud Reproductiva contra Webster, 662 F. Supp. 407 (W.D.Mo. 1987).

(24) Webster contra Servicios de Salud Reproductiva, supra., n. 18, 109 S.Ct. en 3053-3054.

(25) 109 S.Ct. en 3050.

(26) Id. en 3052. 
como tal (27). El Presidente de la Corte Rehnquist y los Vocales White y Kennedy criticaron las pruebas del "trimestre" y de la "viabilidad" usadas en Roe contra Wade, y además señalaron:

"...No vemos la razón por la cual el interés del Estado en proteger la vida humana potencial deba manifestarse sólo recién cuando se presenta la viabilidad..." (28).

Finalmente señalaron que el interés estatal en proteger la vida de los niños por nacer puede ser tan apremiante tanto antes de la "viabilidad" como después de ella.

El Vocal O'Connor adoptó la postura de que el requerimiento de la prueba de viabilidad de la ley de Missouri no era incongruente con el caso Roe contra Wade (29).

Los otros cuatro vocales disidentes, los Jueces Brennan, Marshall, Blackmun y Stevens, ratificaron su adhesión a los principios del caso Roe contra Wade, y en particular a las reglas del "trimestre" y de la "viabilidad" (30).

Hay dos aspectos de la opinión discrepante del Vocal Stevens que debieran ser de particular preocupación para todas las personas dedicadas al estudio de la libertad religiosa. El magistrado se embarca en una discusión de teología y filosofía católica medieval, de una manera profundamente engañosa, en un esfuerzo por demostrar que las enseñanzas morales católicas tradicionales son consistentes con el razonamiento actual en favor del aborto, y que es $l a$ Iglesia Católica la que ha cambiado su posición respecto al aborto

(27) Id. en 3064-3067.

(28) Id. en 3057.

(29) Id. en 3058-3064 (O'Connor, J., confirmando).

(30) Id. en 3067-3079 (Blackmun J., confirmando en parte y discrepando en parte). 
(31). Concluye su opinión con un comentario aún más inquietante, pues dice:

"Refuerza mi conclusión de que el Título Preliminar (de la ley de Missouri) viola la Primera Enmienda, el hecho de que el carácter profundamente divisivo de gran parte del debate nacional sobre el tema del aborto refleja las convicciones religiosas profundas de muchos de sus participantes. El órgano legislativo de Missouri no puede introducir su adhesión a una tradición religiosa particular dentro de este debate..." (32).

Lo que el juez Stevens está diciendo, evidentemente, es que si una ley es un reflejo de principios religiosos, entonces es, por esa razón, constitucionalmente dudosa, si es que no inconstitucional per se.

El Juez Blackmun dijo prácticamente lo mismo en su opinión discrepante en 1986, en un caso donde la Corte sostuvo que una ley del Estado de Georgia que prohibia la sodomía homosexual no violaba la Constitución (33). La consecuencia de la teoría BlackmunStevens sería no sólo que la sociedad puede tener abortos y sodomía, sino también que no debería ni siquiera permitírseles a aquéllos que se oponen a tales comportamientos, exponer y discutir sus puntos de vista, o votar según sus principios, debido a que esos mismos puntos de vista y votos estarían violando la Constitución. La Unión Americana de Libertades Civiles ha defendido esta limitación sobre la libertad religiosa y la libertad de palabra en por lo menos una demanda judicial relacionada con un aborto (34).

(31) Id. en 3083.

(32) Id. en 3085.

(33) Bowers contra Hardwick, 478 U.S. 186,106 S.Ct. 2841, 2854-2855, 92 L. Ed. 2a. 140 (1986) (Blackmun, J., discrepando).

(34) Centro Akron para la Salud Reproductiva, Inc. contra Akron. 479 F. Supp. 1172, 1189-1194 (N.D. Ohio 1979). 
Estos intentos por evitar que personas con principios religiosos participen en el debate público sobre temas de interés general, son un problema tan serio como el aborto mismo. Sin embargo, para regresar al tema de este trabajo, es pertinente preguntarnos: ¿Cuál es el status constitucional del caso Roe contra Wade en la actualidad?". La respuesta debe ser que la ley está en un estado de transición, pero que el ritmo y el grado de cambio no son ciertos. En el caso Webster, un magistrado - Scalia- dijo que Roe contra Wade debería ser abandonado como principio rector (35). Otros tres miembros de la Corte, el Vocal Presidente Rehnquist y los vocales White y Kennedy, expresaron su severa crítica a dicho caso (36). Por otro lado, los otros cuatro magistrados, los jueces Brennan, Marshall, Blackmun y Stevens, respaldan decididamente este caso judicial y rechazan todo intento de regular el aborto (37). La posición de la Vocal O'Connor es menos clara que las de sus ocho colegas.

En noviembre pasado, la Corte oyó los alegatos de dos nuevos casos de aborto. Los puntos en litigio son los siguientes: una ley de Ohio que exige aviso a los padres por parte de los médicos que intentan llevar a cabo abortos en mujeres solteras, no emancipadas, menores de 18 años (38); y una ley de Minnesota que exige que ambos padres sean notificados e impone un periodo de espera de 48 horas antes de que una menor pueda tener un aborto (39). Un tercer caso, referente a una ley de Illinois que establecía ciertas regulaciones para la ejecución de abortos en clínicas especializadas en ellos, también estaba en el calendario de la Corte. Ese caso había sido

(35) 109 S.Ct. en 3064-3067 (Scalia, J., en conformidad).

(36) Id. en 3056-3058 (Opinión Conjunta de Rehnquist, C.J.)

(37) Id. en 3067-3079 (Blackmun, J., en conformidad en parte y en discrepancia en parte).

(38) Ohio contra el Centro Akron para la Salud Reproductiva, No. 88-805 (Discutido en Nov. 29, 1989).

(39) Hodgson contra Minnesota. No. 88-1125; Minnesota contra Hodgson, No. 88-1309 (Ambos discutidos en Nov. 29, 1989). 
programado para ser discutido el 5 de diciembre de 1989, pero las partes lograron un acuerdo y la demanda cayó en desestimiento (40).

También de importancia es el actual litigio sobre la constitucionalidad de la nueva ley de Pennsylvania (41), la que limita el aborto de cuatro maneras:

1. Prohibiendo el aborto de niños con un tiempo de gestación de 24 semanas o más, excepto para evitar la muerte o una lesión permanente y grave a la madre; (42)

2. Prohibiendo los abortos que se intentan realizar únicamente debido al sexo del niño; (43)

3. Estableciendo un período obligatorio de espera de 24 horas antes de llevar a cabo un aborto; (44) y

4. Exigiendo a una mujer casada que desea tener un aborto a dar aviso previo de ello a su esposo (45).

El período de espera de 24 horas y la notificación al esposo han sido declaradas exigencias inconstitucionales por parte de la Corte de Distrito de los Estados Unidos para el Distrito Oriental de Pennsylvania, y la entrada en vigencia de esas disposiciones ha sido temporalmente suspendida (46). Con la sentencia final en la Corte de Distrito, es muy probable que una apelación sea planteada ante la Corte de Apelaciones para el Tercer Circuito, y que el caso sea conocido finalmente por la Corte Suprema.

(40) Turnock contra Ragsdale, No. 88-790.

(41) Acta No. 1989-64 P.L.

42) Id. en 4.

(43) Id. en 2.

(44) Id.

(45) Id. en 3.

(46) Paternidad Responsable del Sureste de Pennsylvania contra Casey, No. 88.3228 (E.D. Pa. 1990). 
Cada uno de estos casos daría a la Corte la oportunidad de dejar de lado el caso Roe contra Wade o, alternativamente, decidir las cuestiones planteadas sobre la base de fundamentos más limitados, como se hizo el año pasado en el caso Webster. Por tanto, el status de Roe contra Wade continúa incierto.

Este caso es la decisión más controvertida de la Corte Suprema, desde la sentencia de 1857 en el caso Dred Scott contra Sandford (47). Y existen importantes similitudes entre ambos casos. Dred Scott fue un esclavo de Missouri que llevó a juicio a su dueño para obtener su libertad. El alegaba que se había vuelto libre cuando un dueño anterior lo había llevado a un Estado y territorio libre (48).

Scott entabló su demanda en una corte federal, arguyendo, entre otras cosas, que él era un ciudadano de Missouri y que como tal tenía derecho a las garantías constitucionales aplicables a los ciudadanos, incluyendo el derecho de entablar juicio ante una corte federal (49). La Corte Suprema sentenció en contra de Dred Scott, señalando que una persona negra -esclava o libre- no era ni podía llegar a ser un "ciudadano" con el propósito de invocar la protección de la Constitución de los Estados Unidos. La Corte dijo que estaba segura de esto porque cada vez que la palabra "ciudadano" era usada en la Constitución se refería a personas que, en la época en que el documento había sido escrito, eran blancas (50). La Corte continuaba diciendo que cualquier ley estatal o territorial que pretendiese proteger a un esclavo haciéndolo libre, era inconstitucional porque privaba a su dueño de su debido derecho de propiedad (51).

(47) 60 U.S. (19 How.) 393, 15 L. Ed. 691 (1857).

(48) Los hechos antecedentes y la trascendencia legal y política del caso se explican en H. Hyman y W. Wiecek, Justicia Equitativa bajo la Ley: Desarrollo Constitucional 1835-1875. 172-190.

(49) Scott había invocado la jurisdicción de la corte federal sobre la base de que había diversidad de ciudadanía entre él, un ciudadano de Missouri y su dueño, un ciudadano de Nueva York.

(50) 15 L. Ed. en 700-710.

(51) 60 U.S. (19 How.) en 450. 
En Roe contra Wade, donde se argüía que un feto es una persona con derecho a la protección de la Constitución de los Estados Unidos, la Corte rechazó este alegato y dijo que puesto que la palabra "persona" era usada en la Constitución para describir, por ejemplo, la elegibilidad para cargos públicos, o los derechos de un acusado en materia penal, la Constitución se refería con ese término a alguien ya nacido (52).

También en este caso la Corte se refirió al niño por nacer sólo como "vida potencial", y continuó diciendo que dicha vida potencial estaba subordinada en todo momento a los derechos de privacidad de la madre (53). Este caso fue resuelto inadecuadamente porque simplemente no existe ningún "derecho de intimidad o privacía" de carácter general que esté garantizado por la Constitución. Lo que la Constitución hace es proteger la intimidad o privacidad en ciertas situaciones: las personas y sus hogares no pueden ser registrados sin una orden judicial de cateo o sin una razón justificable (54); las personas pueden escribir, leer y hablar con libertad (55), y pueden profesar las creencias religiosas que deseen (56). Pero no existe ninguna libertad general exenta de regulación gubernativa sólo porque uno actúa "privadamente", es decir, fuera de la vista del público. La conspiración, el incesto y la crueldad con los animales no están protegidas a pesar de que ellas normalmente ocurren "en privado". No hay nada en el lenguaje o la historia de la Constitución o en la estructura de nuestras instituciones gubernamentales, que pudiese ser alegado para crear un "derecho de intimidad". Este "derecho", anunciado en 1965 y ampliado en Roe contra Wade, no es nada más que una invención judicial.

(52) 93 S.Ct. en 728-729.

(53) Id. en 732.

(54) U.S.A. Constit. Enmienda IV.

(55) U.S.A. Constit. Enmienda I.

(56) Id. 
Es tanto un invento judicial como lo fue la doctrina "sólo-parablancos" del caso Dred Scott.

Roe contra Wade fue resuelto inadecuadamente también porque la Corte, a pesar de su tendencia general a ampliar la protección de la Constitución (57), resolvió que algunas personas - los niños por nacer-, así como las personas negras en el caso Dred Scott, no tienen derecho a la protección constitucional a través del gobierno federal; $y$, si es que ellas tienen algún derecho, éste siempre está subordinado al de su poseedor -en el caso de los esclavos, sus amos; en el caso de los niños por nacer, sus madres.

La Constitución de los Estados Unidos es un documento racional y humano. Desgraciadamente, a veces se le ha dado interpretaciones irracionales e inhumanas. La sentencia del caso Dred Scott fue un ejemplo de ello. Otro ejemplo ocurrió a principios del presente siglo, cuando la Corte Suprema inventó una garantía constitucional de "libertad de contratación" (58), que permitía a los empleadores a tratar a sus empleados de la manera que deseaban - generalmente muy mal. La Corte finalmente abandonó esta teoría ante el respaldo abrumador a la equidad racional de la Nueva Política laboral (59).

Doscientos años de historia constitucional demuestran que las interpretaciones extremistas de la Constitución no perduran. El caso Dred Scott ya no es más el criterio rector de la ley, ni tampoco lo es la "libertad de contratación". Hay razones para esperar que algún día Roe contra Wade también deje de serlo.

(57) Véase A. Cox. La Corte y la Constitución, passim.

(58) Véase, p.e., Lockner contra Nueva York, 198 U.S. 1,25 S.Ct. 539, 49 L.Ed. 937 (1905); Coppage contra Kansas, 236 U.S.cl, 35 S.Ct. 240,59 L.Ed. 441 (1915).

(59) Véase R. Jackson. La Lucha por la Supremacía Judicial. 197-285. 